duration on the probability of dose tapering, after controlling for age, sex, and index advanced therapy.

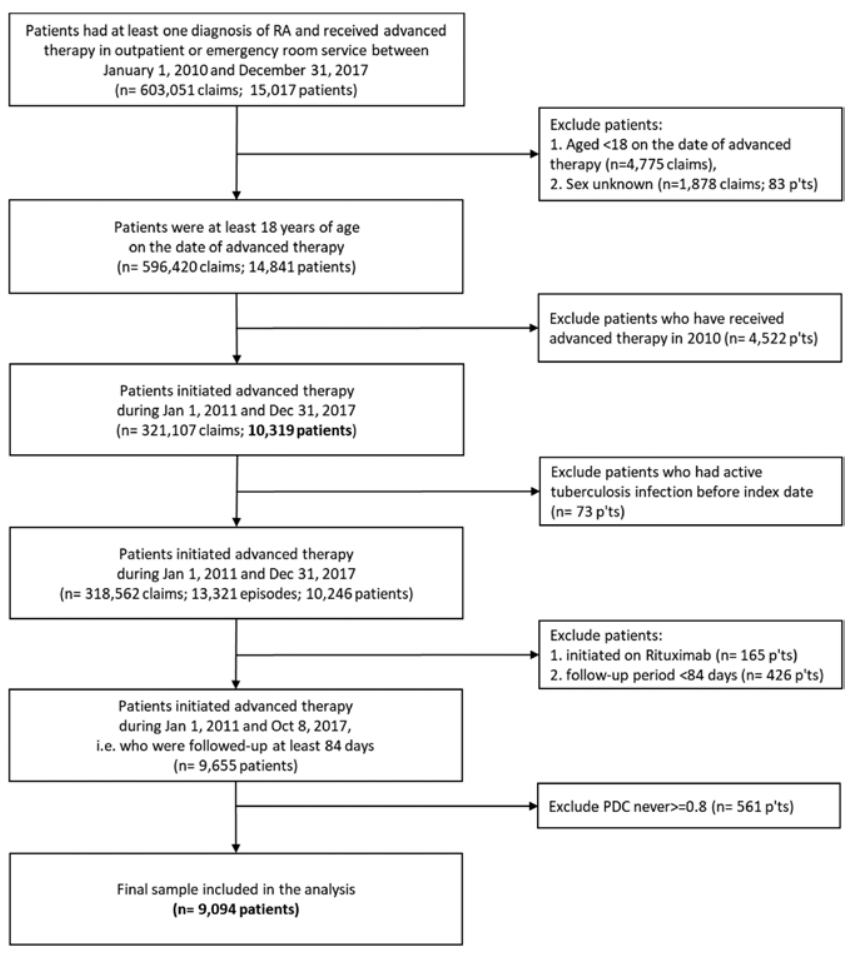

Figure 1. Flow chart of patient selection:

Results: The study comprised 9,094 patients initiated advance treatment for RA, with mean age of 57.3 (SD 13.3) years and $78.8 \%$ were female. The median PDC dropped remarkably after 28 months since treatment initiation (Figure 2). Probability of dose tapering increased significantly when treatment duration $\geq 24$-month $(\mathrm{OR}=2.73, p<0.001)$. When treatment duration $<24$-month, Dose Tapering policy was not significantly associated with tapering prescription. However, implementation of the policy further increased the probability of dose tapering for patients with treatment duration $\geq 24$-month, OR for interaction of policy by duration was 1.17 , and test for interaction $p=0.014$. There were about 3 times increase in the odds of dose tapering probability for patient treated longer than 24 months after the policy implemented in April 2014

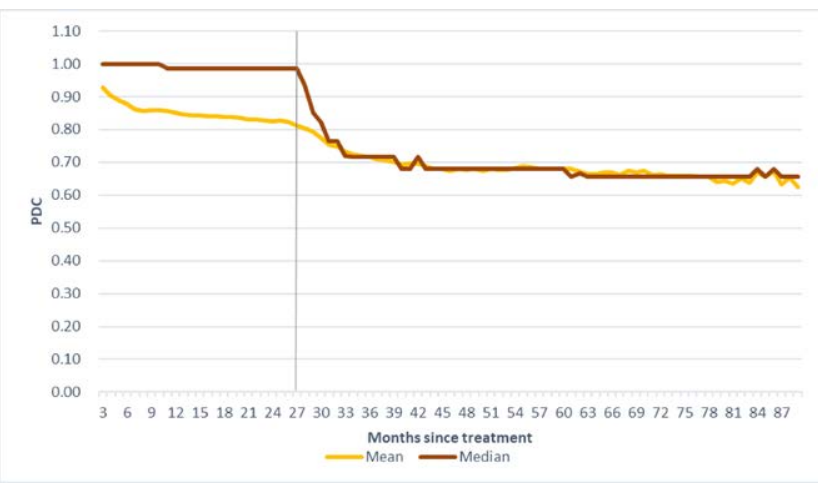

Figure 2. The change of PDC of advanced therapy over the treatment period

Conclusion: For RA patients, PDC of advanced therapy dropped notably after patients received advanced therapy for more than 24 months. The tapering policy implementation significantly increased the probability of dose tapering of advanced therapy in patients with treatment duration $\geq 24$ months.

References:

[1] Lenert A, Lenert P. Clin Rheumatol. 2017;36(1):1-8.

[2] Smolen JS, et al. Ann Rheum Dis. 2017;76(6):960-977.
Table 1. effect of treatment duration and dose tapering policy on the probability of dose tapering

\begin{tabular}{lcccc}
\hline & Odds ratio & $95 \%$ & $\mathrm{Cl}$ & $\mathrm{p}$ value \\
\hline $\begin{array}{l}\text { Effect of Treatment Duration (in pre-policy period) } \\
\geq 24-\text { month vs <24-month }\end{array}$ & 2.73 & $(2.45$, & $3.05)$ & $<.001$ \\
$\begin{array}{l}\text { Effect of Dose Tapering policy (in treatment duration } \\
\quad<24 \text { months) }\end{array}$ & 0.94 & $(0.87$, & $1.01)$ & 0.110 \\
$\begin{array}{l}\text { Post-policy vs Pre-policy } \\
\text { Interaction of Treatment Duration by Dose Tapering } \\
\text { policy }\end{array}$ & 1.17 & $(1.03$, & $1.32)$ & 0.014 \\
$\geq 24-$ month x Post-policy & & & & \\
\hline
\end{tabular}

Dose Tapering policy was implemented on April $1^{\text {st }}, 2014$

Acknowledgments : Research is sponsored by Pfizer Ltd

Disclosure of Interests: Chao-Hsiun Tang: None declared, Chia-Li Chang: None declared, Wen-Yi Shau Employee of: Pfizer, Chih-Yi Hsin Employee of: Pfizer, Ko-Jen Li Speakers bureau: Speaker fee from Pfizer, Abbvie, Roche, Bristol-Myers Squibb, Eli Lilly and Johnson \& Johnson DOI: 10.1136/annrheumdis-2020-eular.1659

\section{SAT0115 COGNITIVE IMPAIRMENT WAS FREQUENT IN PATIENTS WITH RHEUMATOID ARTHRITIS STARTING A BIOLOGIC, WITH SIMILAR RATES OF INHIBITION OR OVERSTIMULATION: AN ANALYSIS OF 84 PATIENTS FROM THE SARIPRO STUDY}

H. Marotte ${ }^{1}$, F. E. Lévy-Weil ${ }^{2}$, R. M. Flipo ${ }^{3}$, T. Schaeverbeke ${ }^{4}$, E. Fakra ${ }^{5}$,

L. Gossec ${ }^{6}{ }^{1}$ INSERM 1059, Rheumatology Department, University Hospital of Saint Etienne, Saint Etienne, France; ${ }^{2}$ Medical Department, Sanofi Genzyme, Gentilly, France; ${ }^{3}$ Rheumatology Department, University Hospital of Lille, Lille, France; ${ }^{4}$ Rheumatology Department, University Hospital of Bordeaux, Bordeaux, France; ${ }^{5}$ Psychiatry Department, University Hospital of Saint Etienne, Saint Etienne, France; ${ }^{6}$ Sorbonne Université, Pitié Salpêtrière Hospital, Paris, France

Background: While cognitive impairment is an issue for patients with rheumatoid arthritis (RA), there are few data available on its frequency and possible link with other outcomes in RA.

Objectives: To assess cognitive impairment in RA and its association with RA and patients' characteristics.

Methods: The SariPRO study (NCT 03449758) was a French multicenter study assessing the effects of sarilumab $200 \mathrm{mg}$ on patient-reported outcomes in patients with moderately to severely active RA with an inadequate response or intolerance to conventional synthetic or biologic DMARDs. This report focuses on baseline data.

The main outcome of this analysis was cognitive impairment evaluated by the cognitive sub-score of the patient-reported multidimensional assessment of mood disorders (MAThyS) scale. This sub-score is scored between 0 (i.e. feeling that thoughts occur slower) and 40 (i.e. racing thoughts) where 20 is the best state. This sub-score was analyzed by tertiles where the lowest tertile indicates general inhibition, the second tertile includes normal states, and the highest tertile indicates general excitation. In addition to the MAThyS total score and sub-scores (Cognition, Emotion, Psychomotricity, Motivation and Sense perception), age, gender, duration of RA, methotrexate use, antibody status (rheumatoid factor/ACPA positivity), fatigue (FACIT-F), anxiety /depression (HADS), as well as patient global assessment (PGA) were collected. Cognitive impairment was defined as inhibition (first tertile) and excitation (third tertile). The association between cognitive inhibition and patients' characteristics (demographic, psychological and disease activity) was estimated by univariate and multivariate logistic regression in an exploratory analysis. There was no imputation of missing data

Results: In all 84 patients were included, characteristics at baseline were as expected for an RA population initiating a biologic: mean (SD) age: 59.1 (12.3) years, $75.0 \%$ female, disease duration 10.0 (10.3) years, rheumatoid factor positivity $76.1 \%$, ACPA positivity $81.3 \%$, and DAS28 5.0 (1.1). The mean (SD) MAThyS cognition score was $18.2(4.9)$. In the exploratory multivariate analysis, factors associated to cognitive inhibition were depression (HADS depression score $\geq$ 8, odds ratio, OR=3.15 [95\% confidence interval, $1.16 ; 8.59], p=0.025)$, emotion inhibition (lower tertile of the MATHYS emotion regulation: $O R=4.76[1.54 ; 14.28]$; $\mathrm{p}=0.007$ ) and low motivation (lower tertile of motivation: $\mathrm{OR}=4.17[1.54 ; 11.11]$; $\mathrm{p}=0.005$ ).

Conclusion: Cognitive impairment was frequent in this population of patients with active RA, with similar rates of cognitive inhibition and cognitive excitation. The results suggest that there may be an association between cognitive inhibition, depression, emotion dysregulation and absence of motivation. Unexpectedly, this 
exploratory analysis did not show an association between cognition impairment and demographic characteristics or disease activity.

References:

[1] Study was sponsored by Sanofi Genzyme

Disclosure of Interests: Hubert MAROTTE Grant/research support from: Bristol Myers Sqibb, Lilly France, MSD, Novartis, Nordic Pharma, Pfizer, SanofiAventis, Consultant of: AbbVie, Amgen, Bristol Myers Sqibb, Lilly France, MSD, Novartis, Nordic Pharma, Pfizer, SanofiAventis, Paid instructor for: Sanofi-Aventis, Speakers bureau: Sanofi-Aventis, Florence E Lévy-Weil Employee of: Sanofi Genzyme employee, René-Marc Flipo Consultant of: Johnson and Johnson, MSD France, Novartis, Sanofi, Speakers bureau: Johnson and Johnson, MSD France, Novartis, Sanofi, Thierry Schaeverbeke: None declared, Eric Fakra Consultant of: Janssen, Lundbeck, Otsuka, Sanofi, Laure Gossec Grant/research support from: Lilly, Mylan, Pfizer, Sandoz, Consultant of: AbbVie, Amgen, Biogen, Celgene, Janssen, Lilly, Novartis, Pfizer, Sandoz, Sanofi-Aventis, UCB

DOI: 10.1136/annrheumdis-2020-eular.5435

\section{SAT0116 COMPARISON OF THE EFFICACY OF ABATACEPT ON ELDERLY AND YOUNG PATIENTS WITH RHEUMATOID ARTHRITIS}

S. Muraoka ${ }^{1}$, Z. Yamada ${ }^{1}$, W. Hirose ${ }^{2}$, H. Kono ${ }^{3}$, S. Yasuda ${ }^{4}$, T. Nanki ${ }^{1}{ }^{1}$ Toho University, Division of Rheumatology, Department of Internal Medicine, Tokyo, Japan; ${ }^{2}$ Hirose Clinic of Rheumatology, Saitama, Japan; ${ }^{3}$ Teikyo University School of Medicine, Department of Internal Medicine, Tokyo, Japan; ${ }^{4}$ Hokkaido university, Department of Rheumatology, Endocrinology and Nephrology, Sapporo, Japan

Background: The widespread use of biologic agents has greatly improved the prognosis of rheumatoid arthritis (RA). On the other hand, elderly patients with RA are relatively increasing. Although achieving low disease activity is a goal for those elderly patients as well as young patients, the efficacy of tumor necrosis factor inhibitors were reported to be equally or slightly less effective in elderly patients than in young patients. There is a lack of evidence for the efficacy of abatacept (ABT) in elderly patients.

Objectives: In this study, we aimed to clarify the efficacy of ABT in elderly and young patients with RA compared to csDMARDs.

Methods: This is a multicenter, open-label, prospective, observational study. All patients with RA enrolled this study are refractory to csDMARDs and have not received any biologics. Either ABT or csDMARDs was administered at the discretion of physicians to elderly (65 years and older) and young (20-64 years) patients (ABT-elderly, ABT-young, control (CTL)-elderly, and CTL-young groups). Comparison was made between 4 groups of patients. The primary study endpoint was a good response by EULAR response criteria at week 24 after administration. The research procedure has been approved by the ethics committee of Toho University School of Medicine (Approval number: A17112).

Results: A total of 219 patients, 127 in the ABT group and 92 in the CTL group, were enrolled in this study. The majority of patients were women $(82.7 \%)$ with a mean age $( \pm S D)$ of $64.9 \pm 13.6$ years $(74.5 \pm 5.9$ years in the elderly group and $52.4 \pm 10.1$ years in the young group). The ABT group had higher disease activity, higher $\mathrm{HAQ}$, and higher steroid use rates and dosage than the CTL group. These were also observed in the elderly group. In the young group, although the ABT group had higher disease activity and higher HAQ than the CTL group, no difference was observed in steroid use rates and dosage. The ABT group more frequently achieved a good response by EULAR response criteria compared to the CTL group at week 24 (58.8\% and $27.2 \%$, respectively, $p<0.0001)$. The ABT group also showed higher efficacy than the CTL group in the elderly and young groups with a good response. Regarding the improvement in DAS28-ESR and DAS28CRP, the ABT group was also superior to the CTL group. There was no difference on efficacy between elderly and young patients from the ABT groups.

Based on propensity score matching for disease activity at baseline, 61 matched pairs of patients treated with ABT or csDMARDs were statistically extracted. Although there was no significant difference in the rate of patients with a good response by EULAR response criteria between the ABT and the CTL groups, the ABT group showed significantly better response than the CTL group in the elderly. Furthermore, the ABT group was superior to the CTL group in improvement in both DAS28-ESR and DAS28-CRP, and similar results were obtained in the elderly. However, there was no significant difference between the ABT group and the CTL group in the young. In addition, elderly patients had significant improvement in DAS28-ESR compared with young patients in the ABT group.

Conclusion: Treatment with ABT showed higher efficacy compared with CTL, particularly in elderly patients with RA.

References:

[1] Harigai M, et al. Mod Rheumatol. 2019;29:747.

[2] Sugihara T, Harigai M. Drugs Aging. 2016;33:97.
Disclosure of Interests: Sei Muraoka Consultant of: Asahikasei Pharma Corp., Speakers bureau: Ono Pharmaceutical Co., Ltd., Eisai Co., Ltd., Asahikase Pharma Corp., and Astellas Pharma Inc., Zento Yamada: None declared, Wataru Hirose: None declared, Hajime Kono: None declared, Shinsuke Yasuda Speakers bureau: Bristol Myers Squibb, Chugai Pharmaceutical Co., Tanabe Mitsubish Parma Co., and GlaxoSmith Kline, Toshihiro Nanki Grant/research support from: Chugai Pharmaceutical Co., Eisai Co., Ltd., Teijin Pharma Ltd., Eli Lilly Japan K.K., Bristol-Myers K.K., Ono Pharmaceutical Co., Ltd., Novartis Pharma K.K., Asahikasei Pharma Corp., Mitsubishi-Tanabe Pharma Co., Astellas Pharma Inc. Ayumi Pharmaceutical Co., Pfizer Japan Inc., Daiichi Sankyo Co., Ltd., Shionogi \& Co., Ltd., Sanofi K.K., Nippon Kayaku Co., Ltd., Yutoku Pharmaceutical Ind. Co. Ltd., UCB Japan Co. Ltd., Nihon Pharmaceutical Co., Ltd., and Bayer Yakuhin, Ltd., Consultant of: UCB Japan Co., Ltd., Eisai Co., Ltd., and Chugai Pharmaceutical Co., Speakers bureau: Mitsubishi-Tanabe Pharma Co., Chugai Pharmaceutical Co., Eisai Co., Ltd., Astellas Pharma Inc., Janssen Pharmaceutical K.K., Ayumi Pharmaceutical Co., Pfizer Japan Inc., Asahikasei Pharma Corp., Sanofi K.K., Novartis Pharma K.K., Eli Lilly Japan K.K., Nippon Kayaku Co., Ltd., Teijin Pharma Ltd., Takeda Pharmaceutical Co., Nippon Boehringer Ingelheim Co., Ltd. and AbbVie GK.

DOI: 10.1136/annrheumdis-2020-eular.1516

\section{SAT0117 OUTCOMES IN WOMEN EXPOSED TO GOLIMUMAB - RESULTS FROM THE COMPANY PHARMACOVIGILANCE DATABASE}

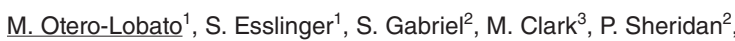

A. Geldhof ${ }^{1} .{ }^{1}$ Janssen Biologics BV, Leiden, Netherlands; ${ }^{2}$ Janssen LLC,

Research \& Development, Horsham, United States of America; ${ }^{3} J a n s s e n ~ L L C$ Research \& Development, Springhouse, United States of America

Background: Rheumatologic disorders and inflammatory bowel disease can affect women of childbearing potential. Golimumab (GLM) is approved for several rheumatologic indications and ulcerative colitis (UC).

Objectives: To characterize pregnancy outcomes in patients treated with GLM data obtained from maternal exposure to GLM are presented.

Methods: This dataset includes individual patient cases reported to the manufacturer through 06 April 2019. Cases included in the analysis were medically confirmed cases of maternal exposures to GLM during pregnancy or within 3 months prior to conception, and a reported pregnancy outcome. Both prospectively reported (ie, pregnancy outcome not known when first reported) and retrospectively reported cases (ie, pregnancy outcome known when first reported) were included. Cases originated from various sources, including spontaneous reporting clinical studies, and registries.

Results: Two hundred eight pregnancy cases (131 rheumatologic indications 43 UC; and 34 other) with 211 reported birth outcomes were identified. Of these 208 pregnancy cases, 119 were prospective and 89 were retrospective. Average maternal age was 31.9 years. Of the 119 prospectively reported pregnancy cases $89(74.8 \%)$ resulted in live births, $19(16.0 \%)$ resulted in spontaneous abortion (of these, $42.1 \%(8 / 19)$ received GLM in combination with methotrexate [MTX]) $10(8.4 \%)$ resulted in induced/elective abortion, and $1(0.8 \%)$ resulted in ectopic pregnancy. Overall, 9 congenital anomalies were reported ( 2 prospective and 7 retrospective cases).

For 183 of the 208 pregnancy cases with reported outcomes, the trimester of exposure to GLM was known. Among the 110 prospectively reported cases, $82(74.5 \%)$ were exposed during trimester 0 or 1 . Of these, 19 had concomitant exposure to MTX, with the following birth outcomes: 8 live births, 8 spontaneous abortions, 3 elective/induced abortions. Eighteen of the prospectively reported cases (16.4\%) were exposed to GLM through trimesters 1-3 and all resulted in live births (none with congenital anomalies; 1 infant with exposure to GLM and MTX was born preterm).

Conclusion: The rates of congenital malformations and spontaneous abortions were consistent with published background rates for the general population. Persistent exposure throughout pregnancy was rare. Limitations of this analysis include the lack of a direct comparison group, the variable amount of data available in the reports, and the possible bias towards reporting more negative outcomes in retrospective cases.

Disclosure of Interests: Marijo Otero-Lobato Shareholder of: Johnson \& Johnson, Employee of: Johnson \& Johnson, Suzan Esslinger Shareholder of: Johnson \& Johnson, Consultant of: Johnson \& Johnson, Novartis, Eli Lilly and Sandoz, Employee of: Johnson \& Johnson, Susan Gabriel Shareholder of: Johnson \& Johnson, Employee of: Johnson \& Johnson, Merck, GSK, Michael Clark Shareholder of: Johnson \& Johnson, Employee of: Johnson \& Johnson, Pamela Sheridan Shareholder of: Johnson \& Johnson, Roche Pharmaceuticals, Employee of: Johnson \& Johnson, Roche, Novartis, Bayer, Anja Geldhof Shareholder of: Johnson \& Johnson, Employee of: Johnson \& Johnson DOI: 10.1136/annrheumdis-2020-eular.2796 